ECCOMAS

Proceedia $8^{\text {th }}$ ECCOM Computational Methods in Structural Dynamics an Thematic Conference on

M. Papadrakakis, M. Fragiadakis (eds.) Streamed from Athens, Greece, 28 - 30 June 2021

\title{
REDUCTION OF HOUSNER'S COEFFICIENT OF RESTITUTION FOR MASONRY WALLS UNDER ONE-SIDED ROCKING
}

\author{
L. Giresini ${ }^{* *}$ and P. Croce ${ }^{2}$ \\ ${ }^{1 *}$ Department of Civil and Industrial Engineering \\ University of Pisa \\ Largo L. Lazzarino, 1, 56126 Pisa \\ email: linda.giresini@unipi.it \\ ${ }^{2}$ Department of Civil and Industrial Engineering \\ University of Pisa \\ Largo L. Lazzarino, 1, 56126 Pisa \\ email: p.croce@ing.unipi.it
}

\begin{abstract}
The out-of-plane dynamics of masonry walls is strongly influenced by seismic input, mass, wall geometry and boundary conditions. Nevertheless, the parameter that mostly affects the dynamic response of a rocking wall is the coefficient of restitution, defined by Housner as ratio of angular velocity after and before an impact on the ground. Such a parameter defines the amount of energy dissipated over motion and is of paramount importance in assessing the seismic vulnerability of a rocking wall, due to the sensitivity of the dynamic response to small changes of it. This paper critically illustrates the preliminary results of an experimental campaign performed on a masonry wall subjected to one-sided rocking. These results are presented in terms of experimental ratios of coefficients of restitution. Two methods for calculating the experimental ratios of coefficients of restitution are described according to whether rocking is one-sided or two-sided. In addition, the paper compares these ratios with those of other experimental tests on two sided rocking and horizontally restrained masonry walls available in the literature. A numerical example is provided by showing that the assumption of a correct coefficient of restitution is crucial for a realistic and correct seismic vulnerability assessment.
\end{abstract}

Keywords: rocking, one-sided, two-sided, coefficient of restitution, masonry, out-of-plane.

ISSN:2623-3347 @ 2021 The Authors. Published by Eccomas Proceedia. Peer-review under responsibility of the organizing committee of COMPDYN 2021. doi:10.7712/120121.8519.18896 


\section{INTRODUCTION}

The appropriate types of analysis that can be carried out on masonry buildings under earthquakes depend on the degree of connection between walls and between walls and horizontal diaphragms, including arches, vaults and roofs [1]-[3]. Seismic retrofitting interventions are generally needed to ensure the box-type behavior; nowadays, seismic consolidation techniques are coupled with low-impact solutions also from an environmental point of view [4], [5]. Nevertheless, when the connection is poor, only local analyses are meaningful for a proper seismic vulnerability assessment. In that case, the most common approach consists in computing collapse loads of local rigid block mechanisms [6]-[10], properly considering floor spectra [11]. An alternative approach, which can be seen as complementary to the mentioned kinematic nonlinear analysis, is the non-linear dynamic analysis or rocking analysis. This investigates the dynamic behavior of the rigid block according to the Housner's equation [12], duly considering the energy dissipated over motion. A synthetic parameter describing this energy dissipation is the coefficient of restitution [13], [14]. The coefficient of restitution can be defined in several ways [8], but they are equivalent only in case of frictionless impact [9].

The coefficient of restitution has a relevant influence on the free damped vibration of a rigid block [15] as well as on its resonance conditions [16], [17]. In the present paper, the coefficient of restitution proposed by Housner is considered, which is defined as ratio of the square root of kinetic energies after and before each impact [12]. Yet, the values of the coefficient of restitution analytically found by Housner [12] as a function of the block slenderness generally overestimate experimental values.

Actually, tests executed on blocks of different materials (e.g. stone, masonry, concrete, etc.) showed scattered values of the coefficient of restitution. For example, tests on rectangular concrete blocks with aluminum base reported [18] were in satisfactory agreement with the Housner predictions ratio: in fact, ratio between experimental and analytical value of coefficient of restitution $e_{E x p} / e_{H}$ was respectively $101 \%$ and $98 \%$. But similar tests performed on non-rectangular blocks [19] and prismatic steel blocks [20] exhibited not recognizable trends. By contrast, at least a qualitative trend of coefficient of restitution with respect to the analytical one can be appreciated when dealing with masonry blocks. Indeed, in general rocking masonry/stone elements dissipate more energy than that is predicted by the Housner's formulation. Literature values refer to ratios of experimental to analytical coefficient of restitution percentage of $85 \%-95 \%$ for free walls [21], [22] and of about $80 \%$ for horizontally restrained walls [22].

This paper analyzes the preliminary experimental results of free-vibration tests executed on an unrestrained masonry wall made of clay brick and cementitious mortar. The dynamics of one sided rocking can be analytically and numerically studied through a modified equation of motion (Section 2). Section 3 illustrates the general features of the experimental campaign and the results in terms of coefficients of restitution, whilst Section 4 compares the so-obtained results with literature values valid for walls of the same typology in two-sided rocking.

\section{ANALYTICAL FORMULATION}

The mechanical model considered for a classical non-linear dynamic analysis is displayed in Figure 1. The wall is assimilated to a perpendicular rigid block of mass $m$, size $R$, polar inertia moment $I_{0}$ rocking around its base. The rigid block is subjected to an acceleration time history $\ddot{u}_{g}(t)$ which can be registered or artificial (spectrum compatible). The rocking wall might be connected to transverse walls of unitary stiffness $K_{c}^{\prime}$ (acting only in compression for 
the sake of simplicity) and to horizontal tie-rods of stiffness $K$. Using the Euler-Lagrange formulation, it is simple to obtain the corresponding terms of the equation of motion $\left(T_{L}\right.$ and $T_{t}$ respectively) as described in detail in [23].

The equation of motion reads:

$$
\begin{gathered}
I_{0} \ddot{\vartheta}+\operatorname{sgn}(\vartheta) m g R \sin A_{\vartheta}+T_{t}+T_{L}=m \ddot{u}_{g} R \cos A_{\vartheta} \\
A_{\vartheta}=\alpha-\operatorname{sgn}(\vartheta) \vartheta
\end{gathered}
$$

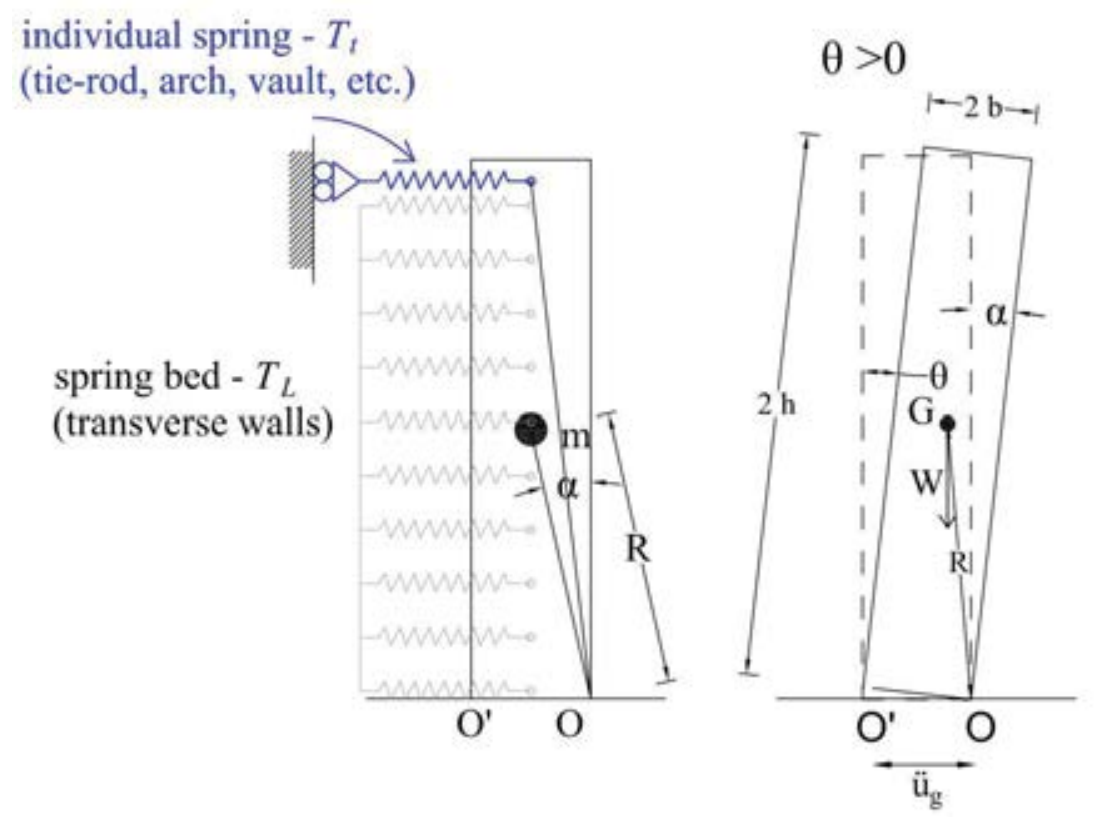

Figure 1: Mechanical model assumed for a rigid block masonry wall.

The energy dissipation is not directly visible in Eq. (1) since it is introduced during the resolution of the equation of motion as change of boundary condition when the block rotation passes from zero to a negative/positive value. Generally, in the dynamics of slender and rectangular rigid blocks the coefficient of restitution as defined by Housner [12] is considered:

$$
e_{H}=1-\frac{3}{2} \sin ^{2} \alpha
$$

Where $\alpha=\operatorname{atan}\left(\frac{h}{b}\right)$ (Figure 1). This expression is obtained by equating the moment of momentum about $\mathrm{O}^{\prime}$ immediately before impact to that immediately after impact on the ground. The coefficient of restitution is expressed as ratio of the square root of the two kinetic energies after and before each impact. As it will be illustrated in Section 3.2, there are different manners to express the coefficient of restitution, depending on whether the rocking is symmetric or not.

\section{EXPERIMENTAL CAMPAIGN ON A MASONRY WALL IN ONE-SIDED ROCKING}

\subsection{Features of the rocking wall and testing set-up}

This section illustrates the tests executed on a clay brick and cementitious mortar wall. The wall, tested in free-vibration, has the following dimensions: height $2.70 \mathrm{~m}$, thickness $0.36 \mathrm{~m}$ and width $1.68 \mathrm{~m}$. Its weight is $29.4 \mathrm{kN}$ and its slenderness ratio, given by the arctangent of 
thickness to height, is 0.133 . The wall is pulled out-of-plane through a tie-rod up to attain a specific displacement $(50 \mathrm{~mm}, 100 \mathrm{~mm}$ and $150 \mathrm{~mm})$ of the wall at $2.56 \mathrm{~m}$ from the base. A detailed description of the experimental tests and of the mechanical features of the wall can be found in [24], [25]. The only difference with the tests already performed is that the hinge is in this case formed at $0.23 \mathrm{~m}$ above the wall base, and not at the wall foundation. This makes the wall stockier as its height diminishes.

Once the wall attains the specified displacement, a quick release system frees it making it rocking. The motion is one-sided, namely the wall impacts against two transverse walls (Figure 2) of length $1.50 \mathrm{~m}$ and thickness $0.12 \mathrm{~m}$ each. The transverse walls have the same mechanical properties as the rocking wall. The displacement and acceleration time-histories are recorded by potentiometric displacement transducers and accelerometers respectively, positioned on the tested wall as shown in [25]. An example of the experimental outputs is reported in Figure 3, where also the velocity time histories, obtained by derivation of the displacement time-histories, are plotted.

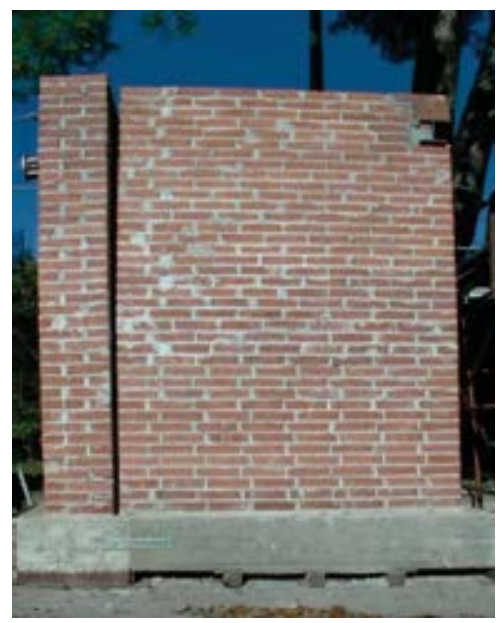

(a)

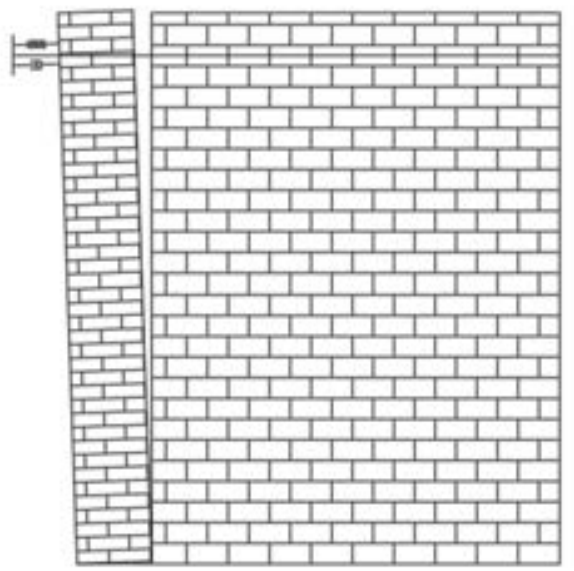

(b)

Figure 2: Masonry wall tested in one-sided rocking.

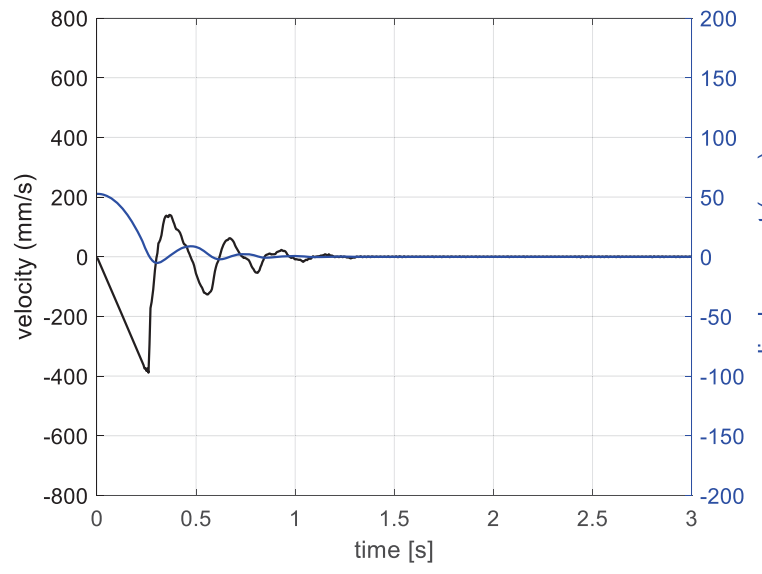

(a)

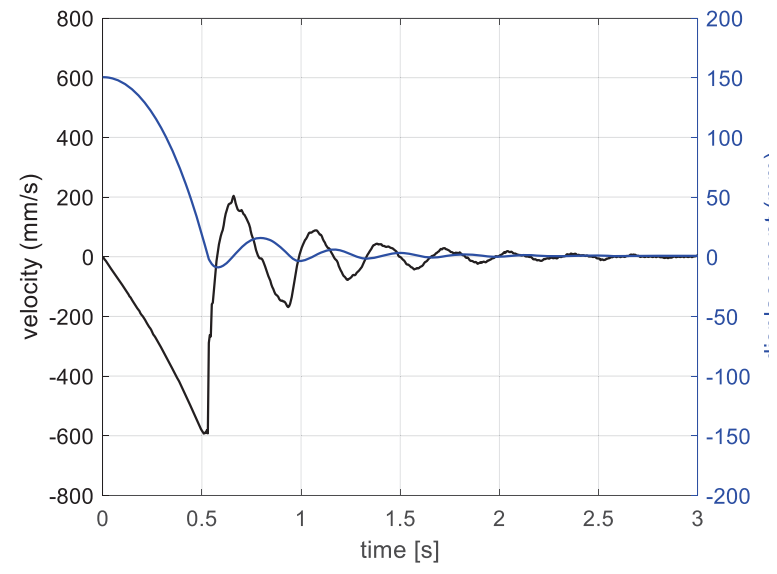

(b)

Figure 3: Selection of experimental results: displacement and velocity time-histories of a point located at 2.56 $\mathrm{m}$ from the wall base: imposed displacement of $50 \mathrm{~mm}$ (a) and of $150 \mathrm{~mm}$ (b). 


\subsection{Computation of coefficient of restitution from experimental results}

These outputs are furtherly elaborated to obtain the experimental coefficients of restitution by two alternative approaches:

1. The traditional one, which computes the experimental coefficient of restitution considering consecutive peaks of velocity. Referring to Figure 4, the coefficient of restitution is calculated as mere ratio of velocity at peak $(i+1)$-th to velocity at peak $i$-th:

$$
e_{\text {exp }}=\left|\frac{v_{i+1}}{v_{i}}\right|<1
$$

regardless of the rotation sign.

2. A more refined one, where two coefficients of restitution are calculated, considering the asymmetric behavior due to the one-sided rocking caused by the impact on transverse walls:

$$
e_{\text {exp }}^{+}=\sqrt{\frac{v_{i+3}^{+}}{v_{i+1}^{+}}} ; \quad e_{\text {exp }}-=\sqrt{\frac{v_{i+2}^{-}}{v_{i}^{-}}}
$$

The need of shifting from Eqn. (3) to Eqn. (4) is due to the fact that, for one-sided rocking, the consecutive negative and positive peaks of velocity are strongly different and the behavior depends on the rotation. Therefore, the calculation of the coefficient of restitution, function of the velocity peaks, should consider such a relevant aspect. This issue was already highlighted for diverse properties of horizontal restraints in [25] and for non-homogeneous walls in [22].

We call "experimental ratio of coefficient of restitution" the term:

$$
r=\frac{e_{\text {exp }}}{e_{H}}
$$

in which $e_{\text {exp }}$ is the experimental value of the coefficient of restitution and $e_{H}$ the analytical value as defined by Housner [12] and recalled in Eq. (2). Three ratios can be therefore defined to calculate the coefficient of restitution:

$$
r=\frac{e_{\text {exp }}}{e_{H}}(\operatorname{method} 1) ; r^{+}=\frac{e_{\text {exp }}^{+}}{e_{H}} \text { and } r^{-}=\frac{e_{\text {exp }}^{-}}{e_{H}}(\operatorname{method} 2)
$$

The wall under examination has a slenderness ratio $\alpha=0.133$, therefore according to Eq. (2) the analytical Housner's coefficient of restitution is $e_{H}=0.974$. 


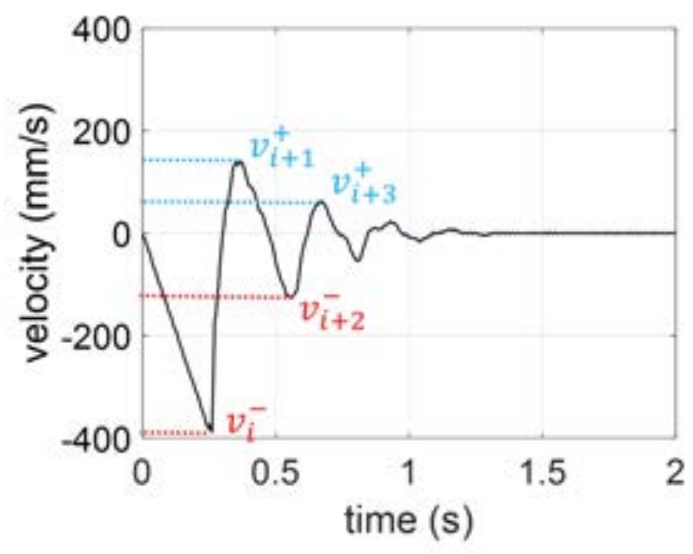

Figure 4: Labels of velocity peaks.

\subsection{Experimental values of coefficients of restitution}

The results in terms of ratios of coefficient of restitution (Eqns. (5)-(6)) are reported in Table 1. Each value is labelled with the imposed displacement and the progressive number of the test. So, for example, test \# 150_2 indicates the second consecutive test where an initial imposed displacement of $150 \mathrm{~mm}$ at the top of the wall has been released. These values are calculated as mean considering the first six impacts, since after them the motion amplitude is negligible. Thus, the two ratios $r^{+}$and $r^{-}$are computed as average of two values, whereas $r$ is computed by considering five values. It is worthy to observe that the average values of $r$ do not sensitively differ from $r^{+}$or $r^{-}$only because the differences between experimental coefficients of restitution are smoothed when the overall average is considered. This aspect is shown in Figure 5: this diagram evidently shows that the average for test $\# 50 \_1$ is very close to $r^{+}=62 \%$ or $r^{-}=$ $59 \%$ (Table 1), although each individual coefficient of restitution markedly change (from 35\% to $88 \%$ ) considering the actual ratios. The difference between $r^{+}$and $r^{-}$is by about $10 \%$. This means that, when the wall impacts against the transverse walls (inward rotation), there is a dissipation of energy by $10 \%$ greater than what occurs in the condition of out-of-plane rocking (outward rotation).

It should be noticed that is not a huge difference, because the length of the transverse walls $(2.0 \mathrm{~m})$ is not enough to produce a rebound effect. Indeed, the oscillations are bilateral as visible in Figure 3 and not unilateral as it should be in actual rocking walls, where the transverse walls are much longer and therefore more rigid. On the contrary, the difference between $r^{+}$and $r^{-}$ is only by $3 \%$ for the test $\# 50$ 1, owing the fact that the initial displacement amplitude is only $50 \mathrm{~mm}$ and therefore the condition of bilateral oscillations is more pronounced. This difference is then not considered as representative, due to the small initial displacement. Consequently, excluding test \#50_1, from Table 1 an average value of 59\% can be estimated for $r_{1}^{-}$, which is a reduction by about $40 \%$ with respect to $r=95 \%$, evaluated for one-sided rocking walls.

\begin{tabular}{lccc} 
test\# & $r^{+}$ & $r^{-}$ & $r$ \\
\hline $150 \_1$ & $67 \%$ & $59 \%$ & $57 \%$ \\
\hline $150 \_2$ & $65 \%$ & $57 \%$ & $59 \%$ \\
\hline $150 \_3$ & $71 \%$ & $61 \%$ & $66 \%$ \\
\hline $100 \_1$ & $68 \%$ & $58 \%$ & $63 \%$ \\
\hline $50 \_1$ & $62 \%$ & $59 \%$ & $59 \%$ \\
\hline
\end{tabular}


Table 1: Mean experimental ratios of coefficients of restitution for the unrestrained wall in one-sided rocking $\left(r^{+}=\right.$outward rotation, $r^{-}=$inward rotation).

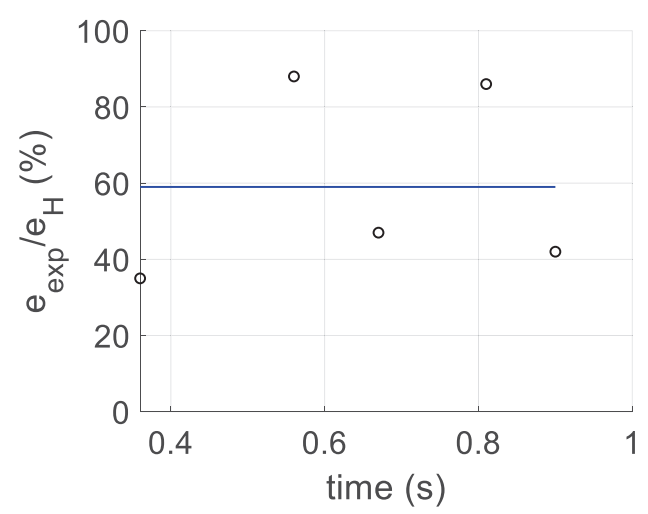

Figure 5: Local values of experimental ratios and average (blue line) for test $\# 50 \_1$.

\section{COMPARISON BETWEEN ONE-SIDED AND TWO-SIDED ROCKING WALLS}

This section illustrates a comparison in terms of experimental ratios of coefficient of restitution found for:

(i) unrestrained walls, in bilateral (two-sided) rocking;

(ii) unrestrained walls, in unilateral (one-sided) rocking;

(iii) walls restrained by dissipative and non-dissipative horizontal restraints.

The first and third condition refer to the experimental tests described in [22], [25], whereas the second condition regards the experimental tests illustrated here.

\subsection{Unrestrained walls in one- and two-sided rocking}

As for the unrestrained walls in two-sided rocking, the mean coefficients of restitution do not vary considering either consecutive peaks or consecutive peaks of the same sign (second and third column of Table 2. In the first test (A_T0_1), there is a greater dissipation of energy, probably because the first impacts, breaking small parts of the mortar joints on the wall base, "smoothen" the rocking surface. For the tested wall, the values of coefficient of restitution range from $88 \%$ to $98 \%$. In [25] the tests were executed also for a slenderer wall of equal characteristics: for it, the results were less scattered, being the minimum $r 95 \%$ and the maximum $r 96 \%$. A reference value of $95 \%$ can be then assumed for the unrestrained walls in two-sided rocking. This ratio is different to that found for in-situ tests performed on historic rubble masonry [22]. This aspect can be explained considering that the in-situ conditions, such as imperfect foundation surface and interference of the rocking wall with the adjacent walls, undoubtedly imply an increase of energy dissipation. The results found in [25] are instead in agreement with the literature results of solid clay brick walls tested in two sided rocking [21], for which an average ratio of $95 \%$ was found.

\begin{tabular}{lllll} 
test\# & $r^{+}$ & $r^{-}$ & $r$ & $r$ (2 impacts) \\
\hline A_T0_1 & & & & \\
\hline A_T0_2 & $93 \%$ & $93 \%$ & $92 \%$ & $97 \%$ \\
\hline A_T0_3 & $97 \%$ & $97 \%$ & $94 \%$ & $94 \%$ \\
\hline
\end{tabular}




\begin{tabular}{lllll} 
A_T0_4 & $97 \%$ & $98 \%$ & $95 \%$ & $99 \%$ \\
\hline A_T0_5 & $91 \%$ & $92 \%$ & $90 \%$ & $88 \%$ \\
\hline
\end{tabular}

Table 2: Mean experimental ratios of coefficients of restitution obtained from experimental tests on the unrestrained wall in two-sided rocking illustrated in [25].

Comparing the results reported in Table 2 and in Table 1, it is clear that the one-sided motion presents much more scattered value of the experimental coefficients of restitution, while their difference increases by $10 \%$ passing from outward rotation to inward rotation (section 3.3). Obviously, in the two-sided rocking the coefficient of restitution does not change significantly when the rotation sign changes.

As described in section 3.3, the average value of $r_{1}^{-}$is $59 \%$, corresponding to a reduction by about $40 \%$ from the value, $r=95 \%$, calculated for two-sided rocking walls. It is therefore of interest to distinguish the amount of energy dissipated by the impact at the ground from that originated by the impact on transverse walls.

Moreover, the presence of transverse walls introduces a non-linearity in the coefficient of restitution as it immediately influences the value of the coefficient of restitution itself. This aspect can be observed by considering the ratios pertaining the first impact only $\left(r_{1}\right)$, or the first two impacts $\left(r_{1}^{+}\right.$and $\left.r_{1}^{-}\right)$. Indeed, the so calculated coefficients of restitution in the inward rotation $\left(r_{1}^{-}\right.$in Table 3 ) are about $55 \%$, that is almost $50 \%$ of the corresponding coefficients of restitution for the two-sided rocking wall (Table 2).

\begin{tabular}{lccc} 
test\# & $r_{1}^{+}$ & $r_{1}^{-}$ & $r_{1}$ \\
\hline $150 \_1$ & $65 \%$ & $52 \%$ & $32 \%$ \\
\hline $150 \_2$ & $66 \%$ & $53 \%$ & $34 \%$ \\
\hline $150 \_3$ & $69 \%$ & $59 \%$ & $37 \%$ \\
\hline $100 \_1$ & $60 \%$ & $52 \%$ & $34 \%$ \\
\hline $50 \_1$ & $64 \%$ & $56 \%$ & $35 \%$ \\
\hline
\end{tabular}

Table 3: Experimental ratios of coefficients of restitution for the first impact of the unrestrained wall in onesided rocking $\left(r_{1}^{+}=\right.$outward rotation, $r_{1}^{-}=$inward rotation $)$.

\subsection{Restrained walls in one-sided and two-sided rocking}

For what concerns the same wall restrained by a damped and stiff horizontal device, a reduction by $5 \%$ of the coefficient of restitution in unrestrained rocking was found in [25]. Therefore, the coefficient of restitution to assume for rocking analysis should be equal (on average) to $90 \%$. The same reduction by $5 \%$ was computed in [22] passing from an unrestrained rubble masonry wall to the same wall restrained by an undamped elastic element. It must be stressed that such a reduction mainly depends on the horizontal restraint type and position, while the influence of masonry texture, material or age, seems negligible.

\section{CASE STUDY: FACADE OF A THREE-NAVE CHURCH}

Numerical analyses are performed in this Section to investigate the relevance of the coefficient of restitution in one-sided rocking motion. The selected case study is the façade of the San Filippo church (Figure 6a) located in Central Italy and struck by the 2016-2017 Central Italy earthquake. During the seismic swarm, a horizontal hinge formed at about 14 meters from the ground, causing the façade to rock and, finally, to overturn and collapse (Figure 6b). 


\subsection{Geometric and mechanical properties}

The façade is made of clay brick and cementitious mortar masonry, having a specific weight around $18 \mathrm{kN} / \mathrm{m}^{3}$. The façade is assimilated to a rocking rectangular block of equivalent height $7.64 \mathrm{~m}$ (obtained considering the equivalence with center of mass and inertia moment of the original geometry), thickness $0.80 \mathrm{~m}$ and width $12.00 \mathrm{~m}$ (Table 4).

The parameters necessary to perform the rocking analysis are the radius vector $R$, the slenderness ratio $\alpha$, the inertia moment $I_{0}$ and the compression spring bed stiffness $K_{c}^{\prime}$ reported in Table 4.

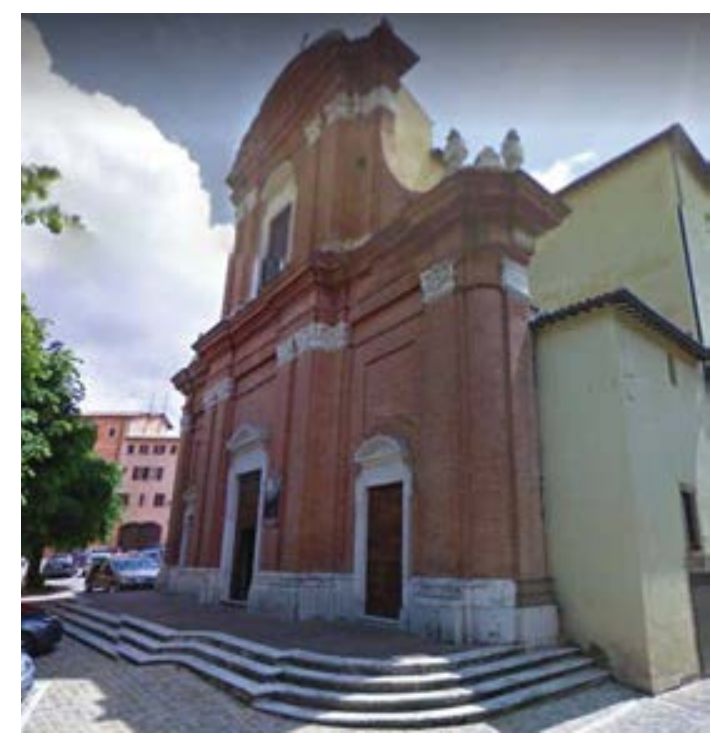

(a)

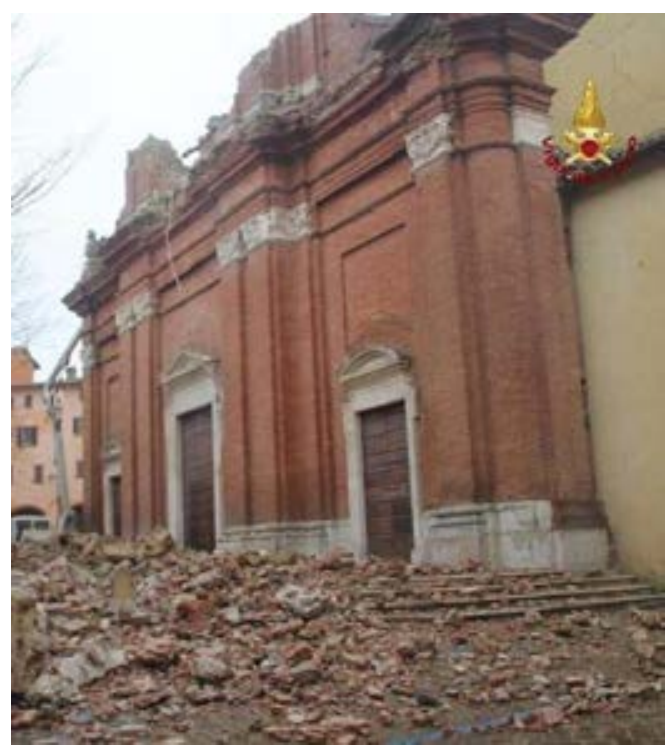

(b)

Figure 6: Case of study: San Filippo Neri’s church in Camerino (Macerata): main façade before (a) and after (b) collapse.

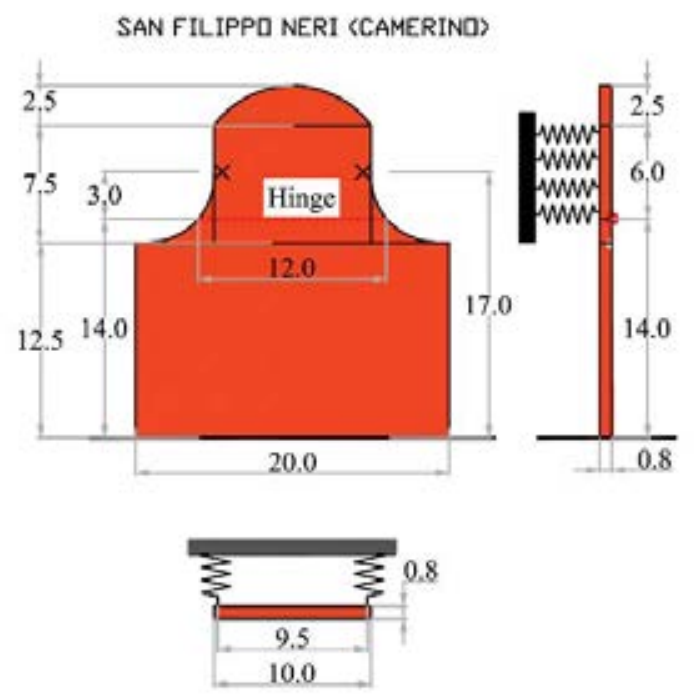

Figure 7: Geometrical dimensions of the case of study (from [26]). 
$\mathrm{I}_{0}$

\begin{tabular}{ccccccc} 
Equivalent height $[\mathrm{m}]$ & Thickness $[\mathrm{m}]$ & Width $[\mathrm{m}]$ & $\mathrm{R}[\mathrm{m}]$ & $a[\mathrm{rad}]$ & {$\left[\mathrm{m}^{4}\right]$} & $K_{c}^{\prime}\left[\mathrm{MN} / \mathrm{m}^{2}\right]$ \\
\hline 7.64 & 0.80 & 12.00 & 3.84 & 0.10 & $2.36 \cdot 10^{6}$ & 750
\end{tabular}

Table 4: Geometric characteristics of the rocking façade.

\subsection{Analysis method}

As already said, the main façade of the church is assumed as rigid block with a compression spring bed simulating the transverse walls. The 40 seismic excitations considered in the study were selected among the most intense ground motions of the 2016-2017 Central Italy earthquake: these earthquakes, belonging to the entire seismic swarm, occurred between August 2016 and January 2017 [26]. Among them, the four that caused the highest rotation amplitudes of the masonry façade - and also its overturning - are here considered.

Their features in terms of Peak Ground Acceleration (PGA) and Peak Ground Velocity (PGV), obtained from the Engineering Strong Motion Database [27], are sumamirzed in Table 5.

\begin{tabular}{lcc} 
Seismic record & PGA & PGV \\
\hline (date and station) & $(\mathrm{g})$ & $(\mathrm{cm} / \mathrm{s})$ \\
\hline 20160824_AMT & 1.10 & 55.31 \\
\hline 20160824_NRC & 0.46 & 37.79 \\
\hline 20161030_CLO & 0.54 & 66.33 \\
\hline 20161030_NRC & 0.62 & 61.33
\end{tabular}

Table 5: Peak Ground Acceleration and Peak Ground Velocity of the considered seismic records [27].

The equation of motion (Eqn. (1)), described in detail in [23], is solved with a MATLAB code to analyze the dynamic behavior of the façade. Since the rocking hinge is not formed at the wall base, the seismic records should be applied after a filtering process, duly taking into account the vibration effects of the substructure. Here, considering the wall geometry, a magnification factor of 1.27 is adopted, as explained in [26], [28].

Two values of coefficients of restitution are considered in the analyses:

1) The Housner's analytical value, labelled with $e_{H}=0.980$ and calculated with Eq. (2).

2) The experimental value of coefficient of restitution, evaluated, as said before, considering the average of the values reported in Table 1, and excluding the test \#50_1. This process results in considering, for the inward rotation, an average coefficient of restitution $e_{e}=0.59$, whereas for the outward rotation the coefficient of restitution is $e_{e}=$ 0.68 .

\subsection{Discussion of results}

Firstly, the strongest records in terms of normalized rotation $(\theta / \alpha)$ amplitude are considered. They occurred in 2016, October $30^{\text {th }}$ and, as visible in Table 5, are associated to the highest PGV values. This aspect confirms the seismic vulnerability of rocking walls to high PGVs [29]. 
Figure 8 displays the time-histories of the normalized rotational response together with the ground acceleration (scaled by the magnification factor of 1.27). At first sight, the adoption of the experimental values of the coefficients of restitution instead of the analytical ones suggested by Housner, leads to generally unsafe-sided results. But it is should be considered that an additional dissipation of energy takes undoubtedly place when transverse walls are present and that disregarding it would lead to over conservative results. Seismic vulnerability assessment executed by neglecting the transverse walls could suggest retrofitting interventions that are actually not needed. This aspect is particularly relevant in case of historic buildings, where it is recommended to avoid unnecessary interventions for the preservation of the cultural heritage. In any case, under the 20161030_NRC, which is not characterized by the highest PGA and PGV, in both cases the overturning is delayed, but not prevented if the reduced experimental value of the coefficient of restitution $\left(e_{e}\right)$ is considered. By contrast, under the 20161030_CLO, adopting $e_{e}$ the façade survives, although its normalized rotation is quite high $(\theta / \alpha>0.5)$.
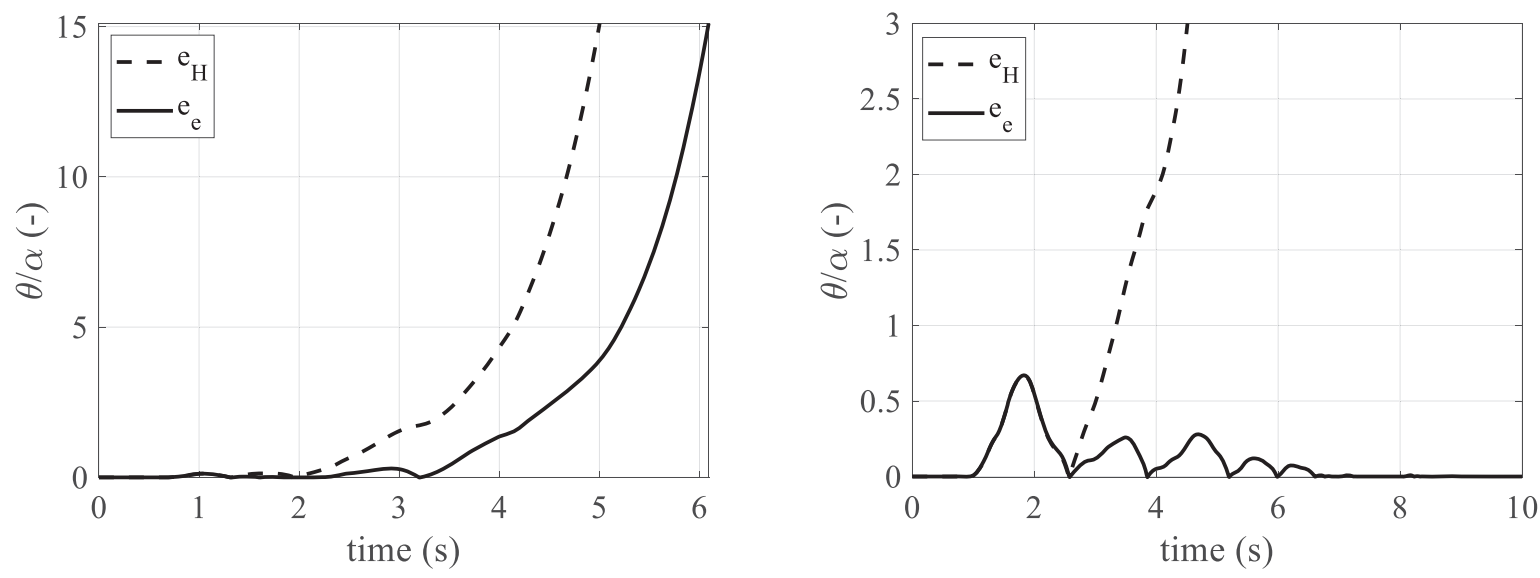

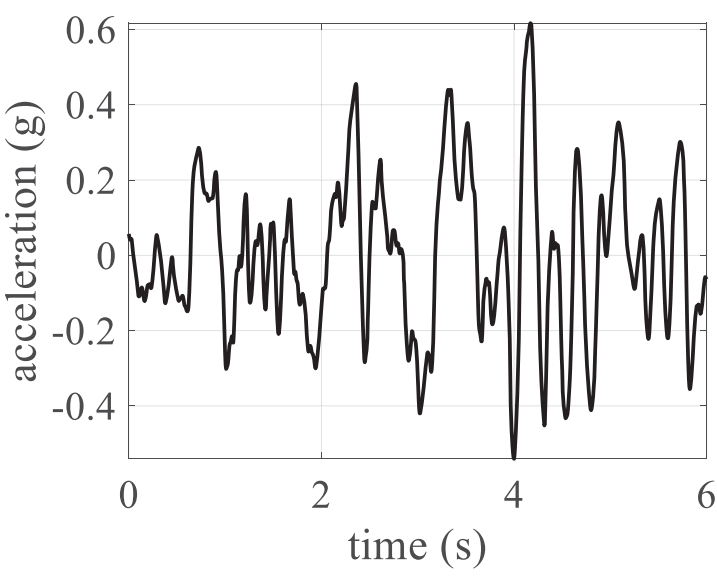

(a)

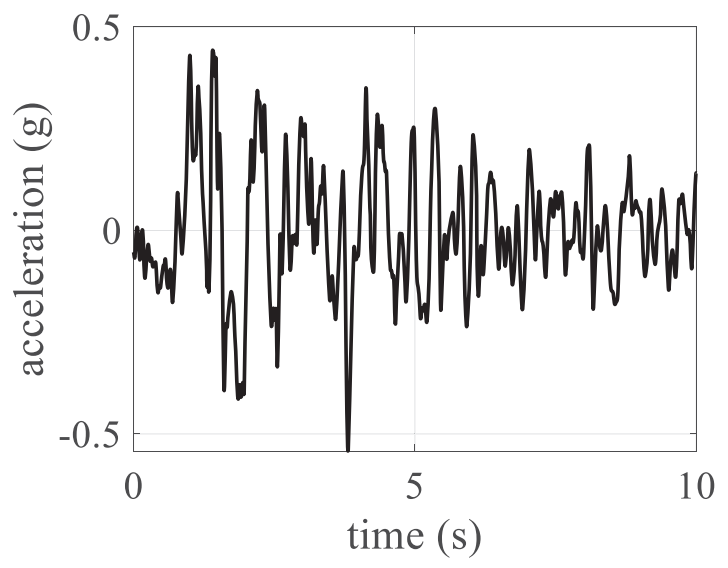

(b)

Figure 8: Rocking response to 20161030_NRC (a) and to 20161030_CLO (b).

Considering the less intense earthquake occurred in 2016, August $24^{\text {th }}$, the passage from the analytical to the experimental value of coefficient of restitution implies a reduction of the amplitude peaks, as evident from Figure 9. In particular, under the earthquake with highest PGA and PGV, the rocking wall experiences a maximum normalized rotation about $60 \%$ that of the maximum rotation computed with the analytical coefficient of restitution. 

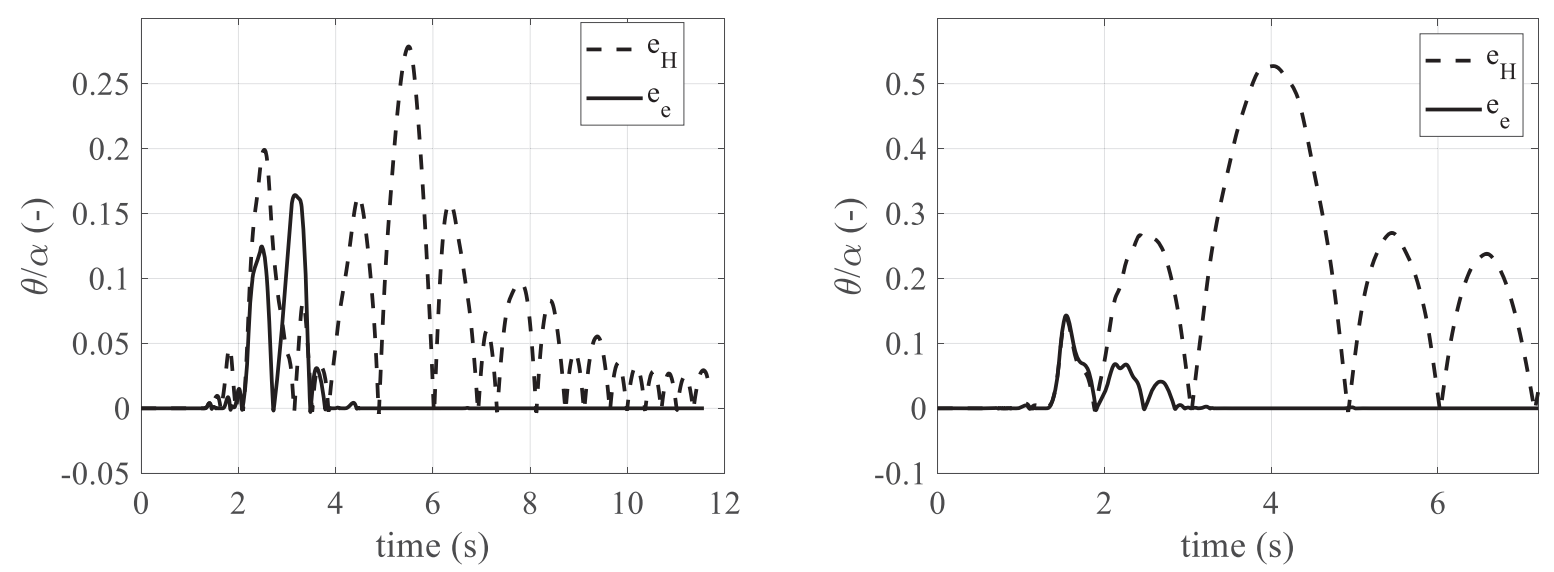

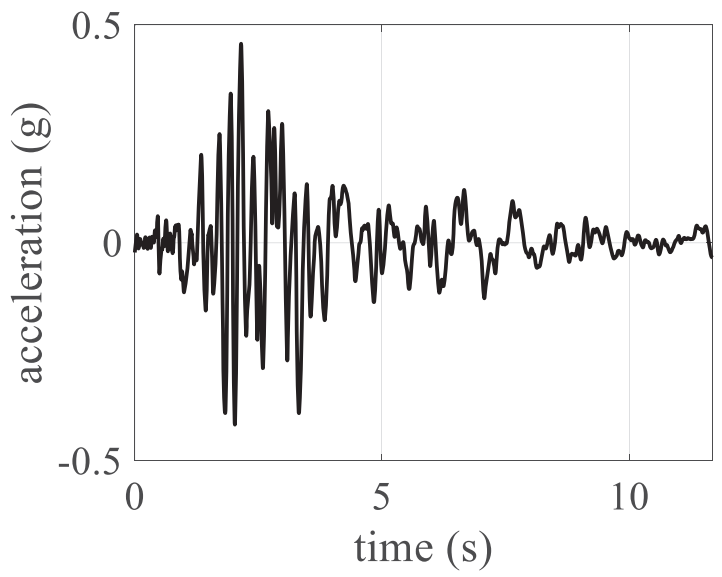

(a)

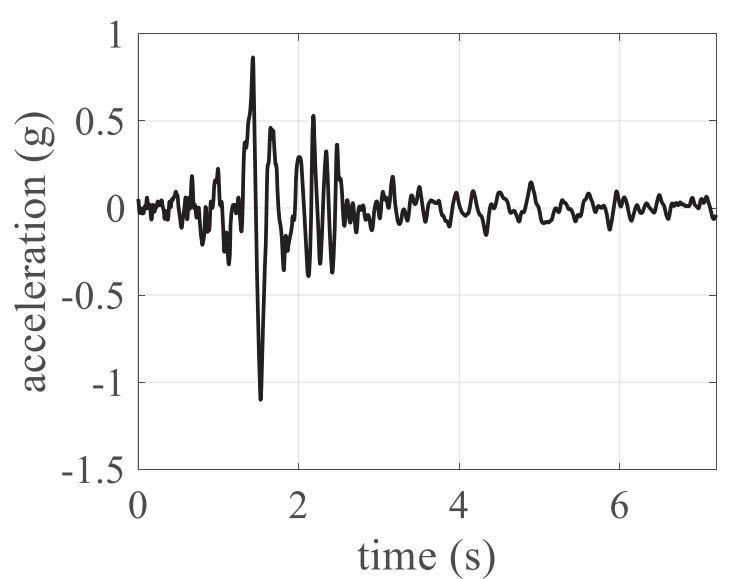

(b)

Figure 9: Rocking response to 20160824_NRC (a) and to 20160824_AMT (b).

Moreover, the maximum response is strongly reduced when the experimental coefficient of restitution is used, indeed it is about $25 \%$ of the maximum rotation computed with its analytical expression. In both cases, the peaks do not occur at the same time, but with the analytical coefficient of restitution the peak is delayed.

\section{CONCLUSIONS}

This paper discussed the experimental results of a set of rocking tests performed on a clay brick and cementitious mortar masonry wall tested in free vibration. The ratios of experimental to analytical coefficients of restitution were computed by the peaks of velocity time histories. Afterwards, their average values were used to perform numerical analyses on a church façade struck by the 2016-2017 Central Italy earthquake. The experimental results of the one-sided rocking wall were compared with those obtained on similar unrestrained and restrained walls in the two-sided rocking condition. The comparison shows that relevant parameters are more scattered in the one-sided rocking condition. Regarding the coefficient of restitution, it can be remarked that it is nearly independent on the rotation sign in the two-sided rocking condition; on the contrary, in the one-sided rocking condition it decreases by about $15 \%$ passing from the outward rotation to the inward rotation. 
The outcomes of the numerical analyses demonstrate that, since the actual experimental values of the coefficient of restitution are generally sensibly lower than the ones estimated according to Housner expression, indirectly considering the influence of transverse walls, their adoption leads to less demanding responses, Consequently, assumption of the Housner coefficients can result too much safe-sided, so implying needs of interventions not always justified. Moreover, the substitution of the Housner coefficients of restitution with more realistic ones, on the one hand, delays but not prevents overturning under the stronger earthquakes, on the other hand maximizes the differences between the stable responses under earthquakes characterized by lower PGAs and PGVs.

In conclusion, since a realistic and critical evaluation of the coefficient of restitution is a key topic in order to avoid unnecessary and expensive retrofitting interventions especially regarding heritage structures, further studies are ongoing.

\section{REFERENCES}

[1] F. Solarino, D. Oliveira, and L. Giresini, Wall-to-horizontal diaphragm connections in historical buildings: A state-of-the-art review. Engineering Structures, 199, 2019.

[2] M. Sassu, L. Giresini, E. Bonannini, and M. L. Puppio, On the Use of Vibro-Compressed Units with Bio-Natural Aggregate. Buildings, 6, 2016.

[3] A. De Falco, L. Giresini, and M. Sassu, Temporary preventive seismic reinforcements on historic churches: numerical modeling of San Frediano in Pisa. Applied Mechanics and Materials, 351, 1393-1396, 2013.

[4] L. Giresini, S. Paone, and M. Sassu, Integrated Cost-Analysis Approach for Seismic and Thermal Improvement of Masonry Building Façades. Buildings, 10, 2020.

[5] L. Giresini, F. Stochino, and M. Sassu, Economic vs environmental isocost and isoperformance curves for the seismic and energy improvement of buildings considering Life Cycle Assessment. Engineering Structures, 233, 111923, 2021.

[6] C. Casapulla, A. Maione, L. U. Argiento, and E. Speranza, Corner failure in masonry buildings: An updated macro-modeling approach with frictional resistances. European Journal of Mechanics, A/Solids, 70, 2018.

[7] C. Casapulla, L. U. Argiento, A. Maione, and E. Speranza, Upgraded formulations for the onset of local mechanisms in multi-storey masonry buildings using limit analysis. Structures, 2021.

[8] C. Casapulla, A. Maione, and L. U. Argiento, Performance-based seismic analysis of rocking masonry façades using non-linear kinematics with frictional resistances: a case study. International Journal of Architectural Heritage, 2019.

[9] C. Casapulla, L. Giresini, L. U. Argiento, and A. Maione, Nonlinear Static and Dynamic Analysis of Rocking Masonry Corners Using Rigid Macro-Block Modeling. International Journal of Structural Stability and Dynamics, 19, 1950137, 2019.

[10] L. Giresini and C. Butenweg, Earthquake Resistant Design of Structures According to Eurocode 8., in Structural Dynamics with Applications in Earthquake and Wind Engineering, 2019, 197-358, .

[11] S. Degli Abbati, S. Cattari, and S. Lagomarsino, Theoretically-based and practiceoriented formulations for the floor spectra evaluation. Earthquake and Structures, 15, 
2018.

[12] G. W. Housner, The behavior of inverted pendulum structures during earthquakes. Bulletin of the Seismological Society of America, 53, 403-417, 1963.

[13] W. J. Stronge, Smooth dynamics of oblique impact with friction. Int. J. Impact Eng., 51, 36-49, 2013.

[14] P. Croce, Nonlinear Dynamics of Swinging Clapper Bells under Arbitrary or Resonant Forcing Functions. Appl.Sci., 10, 2020.

[15] C. Casapulla and A. Maione, Free Damped Vibrations of Rocking Rigid Blocks as Uniformly Accelerated Motions. International Journal of Structural Stability and Dynamics, 17, 1-19, 2016.

[16] C. Casapulla, P. Jossa, and A. Maione, Rocking motion of a masonry rigid block under seismic actions: A new strategy based on the progressive correction of the resonance response | Il moto sotto sisma del blocco murario: Analisi per progressiva correzione della risposta in risonanza. Ingegneria Sismica, 27, 35-48, 2010.

[17] C. Casapulla and A. Maione, Critical Response of Free-Standing Rocking Blocks to the Intense Phase of an Earthquake. International Review of Civil Engineering, 8, 1-10, 2017.

[18] M. Aslam, W. G. Godden, and D. T. Scalise, Earthquake Rocking Response of Rigid Bodies. Journal of the Structural Division, 106, 377-392, 1980.

[19] M. J. N. Priestley, R. J. Evison, and A. J. Carr, Seismic response of structures free to rock on their foundations. Bulletin of the New Zealand National Society for Earthquake Engineering, 11, 141-150, 1978.

[20] P. R. Lipscombe and S. Pellegrino, $\{\mathrm{F}\}$ ree rocking of prismatic blocks. Journal of Structural Engineering, 119, 1387-1410, 1993.

[21] L. Sorrentino, O. AlShawa, and L. D. Decanini, The relevance of energy damping in unreinforced masonry rocking mechanisms. Experimental and analytic investigations. Bulletin of Earthquake Engineering, 9, 1617-1642, 2011.

[22] L. Giresini, M. Sassu, and L. Sorrentino, In situ free-vibration tests on unrestrained and restrained rocking masonry walls. Earthquake Engineering \& Structural Dynamics, 47, 3006-3025, 2018.

[23] F. Solarino, L. Giresini, and P. Croce, Influence of the elasto-plastic behavior of tie-rods in the response of rocking masonry walls through seismic demand hazard curves. , in COMPDYN 2021 8th ECCOMAS Thematic Conference on Computational Methods in Structural Dynamics and Earthquake Engineering M. Papadrakakis, M. Fragiadakis (eds.) Streamed from Athens, Greece, 27-30 June 2021, 2021.

[24] L. Giresini, M. L. Puppio, and F. Taddei, Experimental pull-out tests and design indications for strength anchors installed in masonry walls. Materials and Structures, 2020.

[25] L. Giresini, F. Solarino, F. Taddei, and G. Mueller, Experimental estimation of energy dissipation in rocking masonry walls restrained by an innovative seismic dissipator (LICORD). Bulletin of Earthquake Engineering, 2021.

[26] L. Giresini, C. Casapulla, R. Denysiuk, J. Matos, and M. Sassu, Fragility curves for free 
and restrained rocking masonry façades in one-sided motion. Engineering Structures, 164, 195-213, 2018.

[27] L. Luzi, R. Puglia, E. Russo, and O. WG5, Engineering Strong Motion Database, version 1.0, Istituto Nazionale di Geofisica e Vulcanologia, Observatories \& Research Facilities for European Seismology. . 2016.

[28] Ministero delle infrastrutture e dei trasporti, Circolare applicativa 21 gennaio 2019, $n$. 7, Istruzioni per l'applicazione dell'"Aggiornamento delle "Norme tecniche per le costruzioni"». In Italian. 2019.

[29] L. Giresini, F. Solarino, O. Paganelli, D. V. Oliveira, and M. Froli, One-sided rocking analysis of corner mechanisms in masonry structures: influence of geometry, energy dissipation, boundary conditions. Soil Dynamics and Earthquake Engineering, 123, 357370, 2019. 